\title{
Variable basin ventilation during Mesozoic OAEs constrained by correlated Mo-U isotope signatures
}

\author{
Weyer $\mathrm{S}^{1}$, Montoya Pino $\mathrm{C}^{2}$, VAn DE SChOOTbrugGe \\ $\mathrm{B}^{3}$, Pross J ${ }^{4}$, OSCHMANN W ${ }^{2}$ \\ ${ }^{1}$ Leibniz University Hannover, s.weyer@mineralogie.uni- \\ hannover.de \\ ${ }^{2}$ Goethe University Frankfurt \\ ${ }^{3}$ Universiteit Utrecht \\ ${ }^{4}$ Ruprecht-Karls-Universität Heidelberg
}

During the Mesozoic, oceans experienced periods of enhanced seafloor anoxia at regional or even global scale. Here we show that coupled Mo and $U$ isotope signatures of black shales provide both constraints on the global expansion of seafloor anoxia and regional information on basin ventilation. Recent studies of modern and subrecent organicrich sediments (e.g., Black Sea, Cariaco Basin, Eastern Mediterranean Sea) $)^{1,2}$ have shown that $\delta^{98}$ Mo and $\delta^{238} \mathrm{U}$ are frequently negatively correlated, which is likely a result of variable deep-water renewal times. While fast ventilation results in weakly euxinic conditions associated with significant Mo and $\mathrm{U}$ isotope fractionations, a slowdown of basin ventilation results in a stratified water column with strongly euxinic and isotopically fractionated deep water, generating seawater-like Mo and relatively light $\mathrm{U}$ isotope signatures in the sediments.

Black shales deposited around the late Cretaceous OAE 2 (Demerara Rise) and the early Jurassic T-OAE (Dotternhausen and Truc de Balduc) show a similar negative Mo-U correlation as observed for modern basins, although with a significant shift towards lighter Mo and $\mathrm{U}$ isotope signatures. These signatures indicate enhanced ocean anoxia ${ }^{3,4}$ with an areal extent up to $5-10 \%$ of the global seafoor. Black shales from Demerara Rise indicate only minor changes regarding the expansion of seafloor anoxia between sediments deposited before, during and after OAE2. However, OAE2 sediments indicate more euxinic conditions as a result of a slow down of the proto North Atlantic basin ventilation by a factor of $\sim 2$. Black shales from Dotternhausen and Truc de Balduc plot on identical $\delta^{98} \mathrm{Mo}-\delta^{238} \mathrm{U}$ trends indicating variable basin ventilation in the epicontinental basins of the western Tethys with a significant increase in seafloor anoxia during the T-OAE and decreasing seafloor anoxia during deposition of the Falciferum Zone above.

${ }^{1}$ Andersen et al. (2018) EPSL 503, 58-67. ${ }^{2}$ Brueske et al. (2020) GCA 270, 449-474. ${ }^{3}$ Pearce et al. (2008) Geology 36, 231-234. ${ }^{4}$ Montoya-Pino et al. (2010) Geology 38, 315-318. 